\title{
Research Square \\ DNA Methylation Status of RETN and ADIPOQ Genes in Sporadic Colon Cancer
}

\author{
Rowyda Al-Harithy ( $\nabla$ ralharithy@kau.edu.sa ) \\ King Abdulaziz University
}

Eman Al abdulsalam

King Abdulaziz University

\section{Research Article}

Keywords: DNA methylation, Exon one of RETN gene, ADIPOQ gene, RETN mRNA, Sporadic colon cancer

Posted Date: September 22nd, 2021

DOI: https://doi.org/10.21203/rs.3.rs-891661/v1

License: (c) (i) This work is licensed under a Creative Commons Attribution 4.0 International License. Read Full License 


\section{Abstract}

Background: Colon cancer develops through a complex process that involves epigenetic alterations. Compelling evidence has been achieved that adipocytokines link obesity with colon cancer progression Therefore, understanding the epigenetic modifications in adipokine genes might help in clarifying their role in colon cancer pathogenesis. The aim of the present project was to study the DNA methylation status of RETNand ADIPOQ genes in sporadic colon cancer patients.

Methods: 70 cancerous colon tissue and adjacent paired non-cancerous tissue was used to determine the DNA methylation status using methylation-specific polymerase chain reaction (MS-PCR) assay. Quantitative real-time PCR (qRT-PCR) was used to determine the expression level of RETN and ADIPOQ genes.

Results: In colon cancer tissues, the CpG sites in the three selected promoter regions of ADIPOQ and RETN were hypermethylated in all samples. DNA methylation level at the CpG sites in exon one of the RETN gene exhibited a lower level in the non-cancerous tissue compared to the cancerous tissue and paired blood samples. The RETN mRNA was upregulated.

Conclusion: We postulate that DNA methylation status at the $\mathrm{CpG}$ sites in exon one of the RETNgene might help uncover cancer signatures in sporadic colon cancer and may be used as a biomarker. The upregulation of the RETN mRNA level might play a role in sporadic colon cancer tumorigenesis.

\section{Introduction}

Colon cancer is a hyperplasia of the large intestine and one of the most common causes of cancer-related death in the world ${ }^{1}$. Colon carcinogenesis is a slow and stepwise process that can take years to develop ${ }^{2,3}$. The initiation of colon cancer exhibits additional gene mutations, oncogene activation, loss and gain of chromosomes, microsatellite instability, and $\mathrm{CpG}$ island methylator phenotype (CIMP) ${ }^{3}$. As reported previously in the literature, $20 \%$ of patients diagnosed with colon cancer have familial or congenital mutations in genes that accelerate carcinogenesis to an early age onset. The remaining $80 \%$ tend to develop colon cancer later in life and do not exhibit any obvious genetic causes $^{1}$. Therefore, lifestyle factors that might modify epigenetic patterns, including obesity, have been linked to colon cancer development ${ }^{3}$. A large number of research studies have examined the association between obesity and colon $_{\text {cancer }}^{4-6}$. The literature suggested that increased body mass index correlates with colon cancer development ${ }^{7}$. Therefore, adipokines such as leptin, adiponectin, resistin, and visfatin were measured to investigate their association with colon cancer ${ }^{8-10}$. Resistin, also known as an adipose tissue-specific secretory factor, is a cysteine-rich peptide secreted by adipocytes, immune cells, and epithelial cells that in humans is encoded by the RETN gene ${ }^{11,12}$. The RETN gene is located on chromosome 19p13.2 with four exons and three introns, considering exon one as the untranslated region ${ }^{13}$. Resistin protein is comprised of 90 amino acids and 18 amino acids as a signal sequence. Therefore, resistin pre-peptide has 108 amino acids with $12.5 \mathrm{kDa}$. Resistin is found in two different biological active forms: an oligomer and a trimer ${ }^{14}$. Although resistin is a small adipokine, it is involved in the activation of cell proliferation, survival, and anti-apoptosis ${ }^{15}$. Furthermore, resistin is also involved in cell inflammation that causes cell adhesion and migration that promotes tumorigenesis ${ }^{14}$. ADIPOQ is the gene of adiponectin located on chromosome 3q27 and comprises three exons and two introns, where exons 2 and 3 are coding regions. Adiponectin protein is $30 \mathrm{kDa}$ with 244 amino acids that is expressed exclusively in adipocytes ${ }^{16}$. It has been acknowledged that a low adiponectin level may influence colon cancer carcinogenesis ${ }^{17-19}$. It has been suggested that adiponectin may have a role in the development and progression of cancer via its pro-apoptotic 
and/or anti-proliferative effects. Normally, adiponectin attenuating cancer progression through adenosine monophosphate-activated protein kinase (AMPK).

Epigenetic research has shown that human cancer cells harbor epigenetic alterations ${ }^{20}$. Advancements in the rapidly evolving cancer epigenetic regulations have shown that changes in the epigenetic landscape are a hallmark of cancer. Therefore, disruption of epigenetic mechanisms can lead to altered gene activity and malignant cellular transformation. Significant progress has been made in the basic understanding of how various epigenetic changes such as DNA methylation, histone modification, miRNA expression, and higher-order chromatin structure affect gene activity. DNA methylation is the most broadly investigated epigenetic alteration of genomic DNA and regulating genomic function ${ }^{21}$. Therefore, changes in the methylation state at discrete loci are potentially associated with the control of specific genes related to cancer pathogenesis ${ }^{22}$. DNA hypermethylation has many roles in tissue-specific transcription control. Although tissue-specific DNA hypermethylation occurs more frequently in actively transcribed gene bodies and in intragenic or intergenic enhancers, promoter hypermethylation influences gene expression most notably at promoter regions that are rich in $\mathrm{CpGs}{ }^{23}$. Abnormal increases in methylation at specific DNA sequences can serve as biomarkers for a variety of diseases ${ }^{24}$.

Previous studies have examined RETNDNA methylation ${ }^{25,26}$. But to date, none has focused on the effect of RETN DNA methylation on sporadic colon cancer. Understanding the epigenetic role in RETN may serve as a prognostic, diagnostic marker, and the reversibility of the changes makes it possible to treat sporadic colon cancer disease. Therefore, the present study aimed to study the DNA methylation status of RETN and ADIPOQ genes in sporadic colon cancer patients.

\section{Materials And Methods}

\section{Bioinformatics analysis}

The presence of promoter $\mathrm{CpG}$ islands in the RETN sequence region ranging from $500 \mathrm{bp}$ upstream to $500 \mathrm{bp}$ downstream of the transcription start site was evaluated using the online CpG Island Searcher software (http://dbcat.cgm.ntu.edu.tw/) with default settings. For MS-PCR primers design, bioinformatics link was used as DNA bisulfite conversion tool (https://www.zymoresearch.com/pages/bisulfite-primer-seeker). Then, the design of MS-PCR primers was followed as described by Herman and his team ${ }^{27}$. For the ADIPOQ gene, two sets of primers were chosen from the literature ${ }^{27-29}$.

\section{Subjects}

Sporadic colon cancer Saudi females $(n=39$, age $=59.46 \pm 2.05$ years $)$ and males $(n=31$, age $=60.10 \pm 2.35$ years $)$ patients were included in the study. All participants provided written informed consent after receiving information about the purpose of the study. In some cases, first-degree relatives signed the consent form on behalf of the patients. Tissue samples were obtained from patients assigned for colectomy or endoscopy procedures at Prince Sultan Military Medical City (PSMMC; Riyadh) and King Khalid University Hospital (KKUH; Riyadh). Two samples were collected from each patient, one from cancerous tissue and one from adjacent $(>10 \mathrm{~cm})$ non-cancerous tissue. After surgical removal, the tissue samples from the colectomy procedure were either snap freeze by liquid nitrogen for two minutes or saved in RNA later solution (Invitrogen by Thermo Fisher Scientific, USA) and stored at $-80^{\circ} \mathrm{C}$.

The volunteer's exclusion criteria required individuals to have hereditary colon cancer, treated with either chemo- or radiotherapy. 
The Institutional Review Board approved the study at Prince Sultan Military Medical City (PSMMC), Oncology Department (project no. 995 ref no. \#HAP-01-R-015; approval date: 10 October 2017; Riyadh; Saudi Arabia and King Khalid University Hospital (KKUH), College of Medicine (project no. E-17-2732 ref no. 18/0068/IRB; approval date: 28 December 2017). All experiments were performed in accordance with relevant guidelines and regulations.

\section{DNA extraction and bisulfite treatment}

Genomic DNA was extracted from peripheral blood samples $(2.5 \mathrm{ml})$ using the Puregene Blood Core Kit C (Qiagen, Germany) and from tissue using DNeasy Blood and Tissue Kit (Qiagen, Germany). DNA integrity and concentration were assessed by NanoDrop 2000c spectrophotometer (Thermo-Scientific). DNA (up to 1 $\mu \mathrm{g}$ DNA) was then treated with sodium bisulfite using the EpiTect Fast DNA Bisulfite Kit (Qiagen, Germany) according to manufacturer protocol. CpG Methylated Human Genomic DNA Control (Thermo scientific, USA) was used to ensure conversion efficiency.

\section{Methylation Specific-PCR (MS-PCR)}

To determine the methylation status of the two selected genes (RETN and ADIPOQ), MS-PCR was used for tissues and blood samples. To validate primer design, fully methylated and fully unmethylated DNA controls (EpiTect Control DNA and Control DNA Set (Qiagen) were used. Also, MS-PCR primers were tested against un-treated DNA with bisulfite to test primer's specificity. It was considered only the specific primers. The experiment was duplicated for methylated results to confirm methylation status. Bisulfite-treated DNA templates were PCR amplified using HotStarTaq (5units/ $\mu$ l) from Qiagen (Germany), dNTPs (20mM) from Thermo (USA), 10X buffer from Qiagen (Germany), $10 \mu \mathrm{M}$ each primer, and nuclease-free water up to $25 \mu \mathrm{l}$. Amplification conditions for region and exon one at the RETN gene were: $95^{\circ} \mathrm{C}$ for 15 minutes; $95^{\circ} \mathrm{C}$ for 30 seconds, $59^{\circ} \mathrm{C}$ for 30 seconds, $72^{\circ} \mathrm{C}$ for 1 minute, for 40 cycles, and $72^{\circ} \mathrm{C}$ for 10 minutes. Amplification conditions for promoter region two and three at the ADIPOQ gene were: $95^{\circ} \mathrm{C}$ for 15 minutes; $95^{\circ} \mathrm{C}$ for 10 seconds, (variable for each primer, Table 1 ) for 10 seconds, $72^{\circ} \mathrm{C}$ for 30 seconds, for 40 cycles, and $72^{\circ} \mathrm{C}$ for 10 minutes. The primers for the MS-PCR are shown in Table 1. All MS-PCR amplicons $(10 \mu \mathrm{l})$ were separated on $2 \%$ gel electrophoresis containing GelStarTM Gel Stain (Lonza, USA) and visualized under UV transillumination. 
Table 1

List of primers for MS-PCR

\begin{tabular}{|c|c|c|c|c|c|c|}
\hline Gene & $\begin{array}{l}\text { Primer } \\
5^{\prime}-3^{\prime} \text { seq }\end{array}$ & $\begin{array}{l}\text { Length } \\
\text { (bp) }\end{array}$ & $\begin{array}{l}\text { Annealing } \\
\text { temperature } \\
\left({ }^{\circ} \mathrm{C}\right)\end{array}$ & $\begin{array}{l}\text { Product } \\
\text { size } \\
\text { (bp) }\end{array}$ & $\begin{array}{l}\text { Number } \\
\text { of CpG }\end{array}$ & Reference \\
\hline \multirow[t]{3}{*}{$R E T N^{*}$} & MF1-GTGTAGGAATTCGTGTGTCG & 20 & \multirow[t]{6}{*}{59} & \multirow[t]{3}{*}{166} & \multirow[t]{3}{*}{2} & \multirow{6}{*}{$\begin{array}{l}\text { Designed } \\
\text { manually }\end{array}$} \\
\hline & UF1-GTGTAGGAATTTGTGTGTTG & 20 & & & & \\
\hline & $\begin{array}{l}\text { UM-R1- } \\
\text { AATCTACCCCTAAACCTAAACC }\end{array}$ & 22 & & & & \\
\hline \multirow[t]{3}{*}{$R E T N^{\star \star}$} & $\begin{array}{l}\text { MFEX1- } \\
\text { GTTGTAGGTTTCGTCGTTATCG }\end{array}$ & 22 & & \multirow[t]{3}{*}{223} & \multirow[t]{3}{*}{3} & \\
\hline & $\begin{array}{l}\text { UFEX1- } \\
\text { GGTTGTAGGTTTTGTTGTTATTGGTT }\end{array}$ & 26 & & & & \\
\hline & $\begin{array}{l}\text { UM-REX1- } \\
\text { CTCCAAATTTATTTCCAACTCC }\end{array}$ & 22 & & & & \\
\hline \multirow[t]{4}{*}{$A D I P O Q^{*}$} & MF2-TTAGGTTGGAGTGTAATGGTGC & 22 & \multirow[t]{2}{*}{60} & \multirow[t]{4}{*}{171} & \multirow[t]{4}{*}{1} & \multirow[t]{4}{*}{26} \\
\hline & $\begin{array}{l}\text { MR2- } \\
\text { TAACGAAAATAATAAAACCCCGTC }\end{array}$ & 24 & & & & \\
\hline & $\begin{array}{l}\text { UF2- } \\
\text { TTAGGTTGGAGTGTAATGGTGTG }\end{array}$ & 23 & \multirow[t]{2}{*}{58} & & & \\
\hline & $\begin{array}{l}\text { UR2- } \\
\text { CTAACAAAAATAATAAAACCCCATC }\end{array}$ & 25 & & & & \\
\hline \multirow[t]{4}{*}{$A D I P O Q^{* *}$} & $\begin{array}{l}\text { MF3- } \\
\text { TAATTTTAGTAATTTGGGAGATCGA }\end{array}$ & 25 & \multirow[t]{4}{*}{54} & \multirow[t]{2}{*}{140} & \multirow[t]{4}{*}{1} & \multirow[t]{4}{*}{24} \\
\hline & MR3-AATTACAAACACCTACCATCACG & 23 & & & & \\
\hline & $\begin{array}{l}\text { UF3- } \\
\text { GTAATTTTAGTAATTTGGGAGATTGA }\end{array}$ & 26 & & \multirow[t]{2}{*}{142} & & \\
\hline & $\begin{array}{l}\text { UR3- } \\
\text { AAATTACAAACACCTACCATCACAC }\end{array}$ & 25 & & & & \\
\hline
\end{tabular}

\section{RNA extraction and real-time qPCR}

Total RNA was isolated from blood using PAXGene Blood RNA Kit (Qiagen, Germany) and from tissues using RNeasy Plus Mini Kit (Qiagen, Germany) as the manufacturer described. Total RNA concentration and purity were determined using NanoDrop 2000c spectrophotometer (Thermo- Scientific). 
RETN mRNA and ADIPOQ mRNA were quantified by real-time PCR. 400ng/ $\mu$ l of RNA was used to synthesize complementary DNA (cDNA) by the Reverse Transcription System (Promega, USA) using oligo-dT primers according to the manufacturer's instructions. Then, Real-time PCR amplification reactions from $1 \mu$ l of the synthesized cDNA were prepared using $10 \mu$ l of $2 X$ Taqman ${ }^{\circledR}$ Universal Master Mix (Applied Biosystems, USA), $1 \mu$ l of 20X Taqman ${ }^{\circledR}$ Gene Expression Assays (Applied Biosystems, USA), and nuclease-free water to a final volume of $20 \mu \mathrm{l}$. Q-PCR amplification was performed in a StepOne Plus (Applied Biosystems, USA) using the default setting for the $\Delta \Delta \mathrm{Ct}$ method. Relative gene expression levels were calculated using the comparative $\mathrm{Ct}(\triangle \triangle \mathrm{Ct})$ method and GAPDH (Hs99999905_m1) as the internal control. The expression assays (primers), ADIPOQ (Hs00605917_m1), and RETN (Hs00220767_m1) were purchased from Applied Biosystems. All reactions were carried out in triplicate.

\section{Statistical analysis}

Data are expressed as means \pm standard error of the mean. The $2 \times 2$ contingency tables were used to determine the methylation frequency of MS-PCR results using Fisher's exact test. Comparisons between cancerous tissues and non-cancerous tissues data were made using Wilcoxon matched-pairs signed-rank test as data non-parametric. To evaluate the correlation between blood paired with cancerous tissue, Pearson's correlation or Spearman's rank correlation were performed for parametric and non-parametric data, respectively. Statistical analyses were performed using the computer software GraphPad Prism version 9 (San Diego, USA). All statistical tests considered two-tailed $P$-value $<0.05$ was statistically significant.

\section{Results}

\section{Frequency of methylation}

All the tissues and the paired blood samples at the $\mathrm{CpG}$ sites in the two promoter regions of the $A D I P O Q$ gene showed a high frequency (92-100\%) of DNA methylation in all representative samples. There was also a high level of DNA methylation at the $\mathrm{CpG}$ sites in the promoter region of the RETN gene. Hypermethylation was found in $85.7 \%$ cancerous tissue, $91.1 \%$ non-cancerous tissue, and $83.3 \%$ paired blood samples. The region that is downstream of the transcriptional start site (TSS) in exon one of the RETN gene showed $67.1 \%, 51.1 \%$, and $62.5 \%$ methylation in colon cancerous tissue, non-cancerous tissue, and paired blood samples, respectively (Fig. 1). The Fisher test did not show any significant differences in the frequency of methylation between cancerous tissue paired with noncancerous tissue at the $\mathrm{CpG}$ sites in the region of RETN promoter $(P=0.14)$ and in exon one $(P=0.83)$.

\section{Correlation of hypermethylation between cancerous tissue and paired blood samples}

A positive correlation was found between cancerous tissue paired with blood for both targeted genes (Table 2). The result suggests that blood is a useful non-invasive sample to study both genes for the level of DNA methylation. 
Table 2

Correlation of hypermethylation between cancerous tissue and paired blood samples analysis

\begin{tabular}{|lcc|}
\hline Gene & $\mathbf{r}$ & $\boldsymbol{P}$ value \\
\hline$R E T N^{*}$ & 0.9848 & 0.1112 \\
\hline$R E T N^{* *}$ & 0.8030 & 0.4065 \\
\hline$A D I P O Q^{*}$ & 0.9351 & 0.2307 \\
\hline$A D I P O Q * *$ & 0.7190 & 0.4892 \\
\hline$R E T N^{*}=$ region one, $R E T N^{* *}=$ exon one, $A D I P O Q^{\star}=$ region one and $A D I P O Q^{\star *}=$ region two. \\
\hline
\end{tabular}

\section{Gene expression for ADIPOQ and RETN genes}

Gene expression was examined quantitatively for $A D I P O Q$ and RETN using TaqMan gene expression assay. Sixtyeight tissue samples (cancerous paired non-cancerous tissue) and 21 paired blood samples were assayed. The TaqMan assay could not detect the $A D I P O Q$ gene transcript, either in tissue or blood. The single most striking observation to emerge from the data comparison using paired $t$-test between cancerous and adjacent non-cancerous tissue revealed that $R E T N$ expression is downregulated $(P=0.154)$. This result may implicate DNA methylation in exon one may have an effect on gene activity. Interestingly, there was a significant positive correlation between cancerous tissue and paired blood $(P=0.0006)$. This correlation suggests that blood is a good representative sample to study the RETN gene expression in colon cancer.

\section{Discussion}

Genetic cancer cannot explain sporadic cancer or cancer development in individuals with no family history of cancer. Nonetheless, epigenetic mechanisms can describe the increased risk for the development of sporadic cancer. Thus, epigenetic markers that are consistently dysregulated among cancers present an opportunity to use them as cancer biomarkers for diagnosis, risk assessment, and prediction of therapeutic response. Our study shed light on the DNA methylation of RETN and $A D I P O Q$ genes and their involvement in the progression of sporadic colon cancer to serve as a base for future studies. It is well known that obesity causes dysregulation of adipokines, and that is associated not only with obesity but also with malignancy. Studying aberrant DNA methylation on promoter regions on adipokine genes might help decipher the molecular mechanisms underlying the effect of obesity in sporadic colon cancer development. To the best of our knowledge, this is the first study to investigate DNA methylation status at CpG sites of RETNand ADIPOQ genes in sporadic colon cancer tissue.

The number of genes known to undergo promoter hypermethylation in cancer has grown substantially. Our exploring study using cancerous tissue, matched normal tissue, and paired blood samples from colon cancer patients demonstrated hypermethylation at the $\mathrm{CpG}$ sites in the two promoter regions of the ADIPOQ gene. Additionally, the expression level of adiponectin was undetectable. Our result agrees with previous studies. Haghiac and his team showed that obesity in pregnancy is associated with an increase in ADIPOQ DNA methylation and lower mRNA concentration ${ }^{28}$. A year later, another group have observed hypermethylation in the same promoter region that we explored (region one) and confirmed down-regulation for adiponectin level in prostate cancer tissue via promoter hypermethylation ${ }^{29}$. Given that hypermethylation is an important factor in regulating gene expression, we hypothesize that the undetected $A D I P O Q$ gene transcript in our study is due to the frequency or location of the DNA 
methylation on the $A D I P O Q$ promoter. Another possible explanation is the developmental stages of cancer. It is well known that the role of adiponectin in colorectal neoplasm is a direct anti-tumorigenic effect ${ }^{29}$. So, deficiency of adiponectin seems to be associated with the development of an early neoplasm rather than advanced colon cancer. Therefore, we suggest that the promoter hypermethylation that we observed in the present study is not sporadic colon cancer-associated methylation but might be associated with the repression of the ADIPOQ mRNA transcription.

We also observed hypermethylation at the $\mathrm{CpG}$ sites in the promoter region of RETNgene in cancerous tissue, adjacent normal tissue, and paired blood samples. Whereas DNA methylation level at the CpG sites in exon one of the RETN gene exhibited a lower level in the non-cancerous tissue compared to the cancerous tissue, and the blood samples. The region that is downstream of the transcriptional start site (TSS) in exon one of the RETN gene showed a cancer-specific methylation pattern. This region was more informative because less methylation in the adjacent non-cancerous tissue than the cancerous tissue was detected. This finding raises the hypothesis that methylation at the $\mathrm{CpG}$ sites in exon one might contribute to the disease and can be suggested as a biomarker to sporadic colon cancer. Also, the outcome also suggests that the methylation pattern in exon one of the RETN may be important for understanding the molecular mechanisms linking to the development of the disease. Here we believe we are identifying novel colon cancer DNA methylation changes associated with sporadic colon cancer. We postulate that DNA methylation at the $\mathrm{CpG}$ sites in exon one of the RETN gene might help uncover cancer signatures in colon cancer and may be used as a prognostic biomarker.

Moreover, our data showed that the RETNmRNA was upregulated in the tissues and blood samples. Previous studies confirmed a higher level of resistin in patients with colon cancer than healthy controls, indicating that resistin levels may be positively correlated with the risk of colon cancer ${ }^{30-32}$. In 2002, Sadashiv and his group measured resistin mRNA in subcutaneous adipose tissue (SAT) in postmenopausal obese and non-obese women and showed that the expression of resistin in serum and the level of RETN mRNA were upregulated in postmenopausal obese women ${ }^{33}$. In contrast, when resistin was measured in visceral adipose tissue (VAT), it was found that the expression of resistin was downregulated at the transcriptional level and upregulated in the serum of the postmenopausal obese group ${ }^{33}$. They postulated that the mRNA resistin level variation in both tissues could pinpoint a posttranslational mechanism occurrence. Therefore, they suggested that additional research is needed to explore the regulation and biological function of resistin in humans.

Although the role of resistin in colon cancer is far from being elucidated, several mechanisms may be involved in explaining these outcomes. In fact, a few years later it was reported that the plasma resistin was inversely associated with the extent of methylation at SNP - 420 in the promoter of the RETNgene ${ }^{34}$. They suggested that the association could have genetic and epigenetic effects on the expression of the RETN gene and the level of plasma resistin. The result was supported by another group who reported the effect of hypomethylation on the RETN gene on PCOS causing upregulation of resistin mRNA ${ }^{34}$. Given that hypermethylation is an important factor in regulating gene expression, we suggest that the hypermethylation at the $\mathrm{CpG}$ sites in the promoter region of the RETN gene is not colon cancer-associated methylation. It might have an effect on RETN gene expression, and hence, resistin action.

While DNA methylation as cancer biomarkers is still a relatively new area, the advantages of using DNA methylation as a cancer marker are evident. Furthermore, the upregulation of RETNmRNA in the tissues and blood samples may regard as a fundamental role of DNA methylation in the regulation of gene activity. It is known that the development of $\mathrm{CpG}$ island hypermethylation profiles for every form of human tumors will yield valuable pilot clinical data in monitoring and treating cancer patients. Therefore, more analysis is needed to determine if DNA methylation in exon 
one region is truly relevant for sporadic colon cancer tumorigenesis and the increased expression of the RETNgene. The expectations are high.

Although the sample size in this study was small, the design of this study was relatively strong because the normal tissue samples near the cancerous tissue were taken from the same colon cancer patients. Therefore, upcoming research should address the prognostic potential of methylation profiles in sporadic colon cancer tissue, especially primary tumors of early-stage colon cancer.

In the future, the investigation of DNA methylation can be helpful in early cancer detection. Understanding the differentiation-related roles for tissue-specific DNA hypermethylation is important for evaluating the biological functionality of disease-related DNA hypermethylation. Therefore, challenging future clinical applications to colon cancer is the inclusion of epigenetic markers in diagnostic, treatment-decision assays, and the development of treatments aiming at improving patients' outcomes and enhance the quality of life.

\section{Conclusion}

DNA methylation is a useful biomarker for predicting tumor recurrence patterns and colon cancer patient survival. Our findings provide further characterization of the methylation profile in the sporadic colon cancer disease that might help in the identification of novel targets to be used for improving patients' outcomes. Our study indicates that hypermethylation at the $\mathrm{CpG}$ sites in the two regions of the $A D I P O Q$ promoter has an effect on gene expression and may play a role in colon cancer tumorigenesis. We postulate that DNA methylation at the CpG sites in exon one of the RETN gene might help uncover cancer signatures in colon cancer and may be used as a prognostic biomarker.

\section{Declarations}

\section{Compliance with ethical standards}

Funding: There has been no financial support for this work.

Disclosure statement: The authors declare that they have no competing interests.

Data availability statement: The data that support the findings of this study are available on request from the corresponding author. The data are not publicly available due to privacy or ethical restrictions.

Ethical approval: This study was approved by the Research Ethics Committee of Prince Sultan Military Medical City, Riyadh, Saudi Arabia and King Khalid University Hospital (KKUH), College of Medicine, Riyadh, Saudi Arabia.

Contributorship: Rowyda N. Al-Harithy and Eman A. Al-Abdulsalam are equally contributed to the design and implementation of the research, to the analysis of the results and to the writing of the manuscript.

Acknowledgment: This work would not have been possible without the support of Dr. Sultan Al-Sedairy (Research Centre Executive Director, Riyadh). We would like to express our gratitude to Dr. Sultan who gave us the golden opportunity to work at the research center.

\section{References}

1. Haggar, F. A. \& Boushey, R. P. Colorectal cancer epidemiology: incidence, mortality, survival, and risk factors. Clin Colon Rectal Surg 22, 191-197, doi:10.1055/s-0029-1242458 (2009). 
2. Pitule, P., Čedíková, M., Třeška, V., Králíčková, M. \& Liška, V. Assessing colorectal cancer heterogeneity: one step closer to tailored medicine. Journal of Applied Biomedicine 11, 115-129, doi:https://doi.org/10.2478/v10136012-0035-6 (2013).

3. Rao, C. V. \& Yamada, H. Y. Genomic instability and colon carcinogenesis: from the perspective of genes. Frontiers in oncology 3, 130-130, doi:10.3389/fonc.2013.00130 (2013).

4. Neugut, A. I. et al. Obesity and colorectal adenomatous polyps. Journal of the National Cancer Institute 83, 359361, doi:10.1093/jnci/83.5.359 (1991).

5. Dai, Z., Xu, Y. C. \& Niu, L. Obesity and colorectal cancer risk: a meta-analysis of cohort studies. World journal of gastroenterology 13, 4199-4206, doi:10.3748/wjg.v13.i31.4199 (2007).

6. Bardou, M., Barkun, A. N. \& Martel, M. Obesity and colorectal cancer. Gut 62, 933-947, doi:10.1136/gutjnl-2013304701 (2013).

7. Murphy, T. K., Calle, E. E., Rodriguez, C., Kahn, H. S. \& Thun, M. J. Body mass index and colon cancer mortality in a large prospective study. American journal of epidemiology 152, 847-854, doi:10.1093/aje/152.9.847 (2000).

8. Nakajima, T. E. et al. Adipocytokines as new promising markers of colorectal tumors: adiponectin for colorectal adenoma, and resistin and visfatin for colorectal cancer. Cancer science 101, 1286-1291, doi:10.1111/j.13497006.2010.01518.x (2010).

9. Fazeli, M. S. et al. Circulating levels of novel adipocytokines in patients with colorectal cancer. Cytokine 62, 8185, doi:10.1016/j.cyto.2013.02.012 (2013).

10. Riondino, S. et al. Obesity and colorectal cancer: role of adipokines in tumor initiation and progression. World journal of gastroenterology 20, 5177-5190, doi:10.3748/wjg.v20.i18.5177 (2014).

11. Jonas, M. I. et al. Adiponectin/resistin interplay in serum and in adipose tissue of obese and normal-weight individuals. Diabetology \& Metabolic Syndrome 9, 95, doi:10.1186/s13098-017-0293-2 (2017).

12. Booth, A., Magnuson, A., Fouts, J. \& Foster, M. Adipose tissue, obesity and adipokines: role in cancer promotion. Hormone molecular biology and clinical investigation 21, 57-74, doi:10.1515/hmbci-2014-0037 (2015).

13. Wang, H., Chu, W. S., Hemphill, C. \& Elbein, S. C. Human resistin gene: molecular scanning and evaluation of association with insulin sensitivity and type 2 diabetes in Caucasians. The Journal of clinical endocrinology and metabolism 87, 2520-2524, doi:10.1210/jcem.87.6.8528 (2002).

14. Acquarone, E., Monacelli, F., Borghi, R., Nencioni, A. \& Odetti, P. Resistin: A reappraisal. Mechanisms of ageing and development 178, 46-63, doi:10.1016/j.mad.2019.01.004 (2019).

15. Yang, C. C. et al. Activation of AMP-activated protein kinase attenuates hepatocellular carcinoma cell adhesion stimulated by adipokine resistin. BMC cancer 14, 112, doi:10.1186/1471-2407-14-112 (2014).

16. Yang, W. S. \& Chuang, L. M. Human genetics of adiponectin in the metabolic syndrome. Journal of molecular medicine (Berlin, Germany) 84, 112-121, doi:10.1007/s00109-005-0011-7 (2006).

17. Fenton, J. I., Birmingham, J. M., Hursting, S. D. \& Hord, N. G. Adiponectin blocks multiple signaling cascades associated with leptin-induced cell proliferation in Apc Min/+ colon epithelial cells. International journal of cancer 122, 2437-2445, doi:10.1002/ijc.23436 (2008).

18. Gulcelik, M. A. et al. Associations between adiponectin and two different cancers: breast and colon. Asian Pacific journal of cancer prevention : APJCP 13, 395-398, doi:10.7314/apjcp.2012.13.1.395 (2012).

19. Inamura, K. et al. Prediagnosis Plasma Adiponectin in Relation to Colorectal Cancer Risk According to KRAS Mutation Status. Journal of the National Cancer Institute 108, doi:10.1093/jnci/djv363 (2016). 
20. Jones, P. A. \& Baylin, S. B. The fundamental role of epigenetic events in cancer. Nature Reviews Genetics 3, 415428, doi:10.1038/nrg816 (2002).

21. Okugawa, Y., Grady, W. M. \& Goel, A. Epigenetic Alterations in Colorectal Cancer: Emerging Biomarkers. Gastroenterology 149, 1204-1225.e1212, doi:10.1053/j.gastro.2015.07.011 (2015).

22. Baylin, S. B. \& Jones, P. A. Epigenetic Determinants of Cancer. Cold Spring Harb Perspect Bio/ 8 , doi:10.1101/cshperspect.a019505 (2016).

23. Kundaje, A. et al. Integrative analysis of 111 reference human epigenomes. Nature 518, 317-330, doi:10.1038/nature14248 (2015).

24. Ehrlich, M. DNA hypermethylation in disease: mechanisms and clinical relevance. Epigenetics 14, 1141-1163, doi:10.1080/15592294.2019.1638701 (2019).

25. Houshmand-Oeregaard, A. et al. Differential adipokine DNA methylation and gene expression in subcutaneous adipose tissue from adult offspring of women with diabetes in pregnancy. Clin Epigenetics 9, 37, doi:10.1186/s13148-017-0338-2 (2017).

26. Onuma, H. et al. Dual Effects of a RETN Single Nucleotide Polymorphism (SNP) at -420 on Plasma Resistin: Genotype and DNA Methylation. The Journal of clinical endocrinology and metabolism 102, 884-892, doi:10.1210/jc.2016-2417 (2017).

27. Herman, J. G., Graff, J. R., Myöhänen, S., Nelkin, B. D. \& Baylin, S. B. Methylation-specific PCR: a novel PCR assay for methylation status of CpG islands. Proc Natl Acad Sci U S A 93, 9821-9826, doi:10.1073/pnas.93.18.9821 (1996).

28. Haghiac, M. et al. Patterns of adiponectin expression in term pregnancy: impact of obesity. The Journal of clinical endocrinology and metabolism 99, 3427-3434, doi:10.1210/jc.2013-4074 (2014).

29. Tan, W. et al. Adiponectin as a potential tumor suppressor inhibiting epithelial-to-mesenchymal transition but frequently silenced in prostate cancer by promoter methylation. The Prostate 75, 1197-1205, doi:https://doi.org/10.1002/pros.23002 (2015).

30. Gonullu, G., Kahraman, H., Bedir, A., Bektas, A. \& Yücel, I. Association between adiponectin, resistin, insulin resistance, and colorectal tumors. International Journal of Colorectal Disease 25, 205-212, doi:10.1007/s00384009-0828-6 (2010).

31. Yang, G. et al. Circulating Resistin Levels and Risk of Colorectal Cancer: A Meta-Analysis. Biomed Res Int 2016, 7367485-7367485, doi:10.1155/2016/7367485 (2016).

32. Farahani, H. et al. Insulin Resistance and Colorectal Cancer Risk: the Role of Elevated Plasma Resistin Levels. Journal of gastrointestinal cancer 51, 478-483, doi:10.1007/s12029-019-00260-7 (2020).

33. Sadashiv et al. Over expression of resistin in adipose tissue of the obese induces insulin resistance. World $J$ Diabetes 3, 135-141, doi:10.4239/wjd.v3.i7.135 (2012).

34. Onuma, H. et al. Dual Effects of a RETN Single Nucleotide Polymorphism (SNP) at -420 on Plasma Resistin: Genotype and DNA Methylation. The Journal of Clinical Endocrinology \& Metabolism 102, 884-892, doi:10.1210/jc.2016-2417 (2017).

\section{Figures}



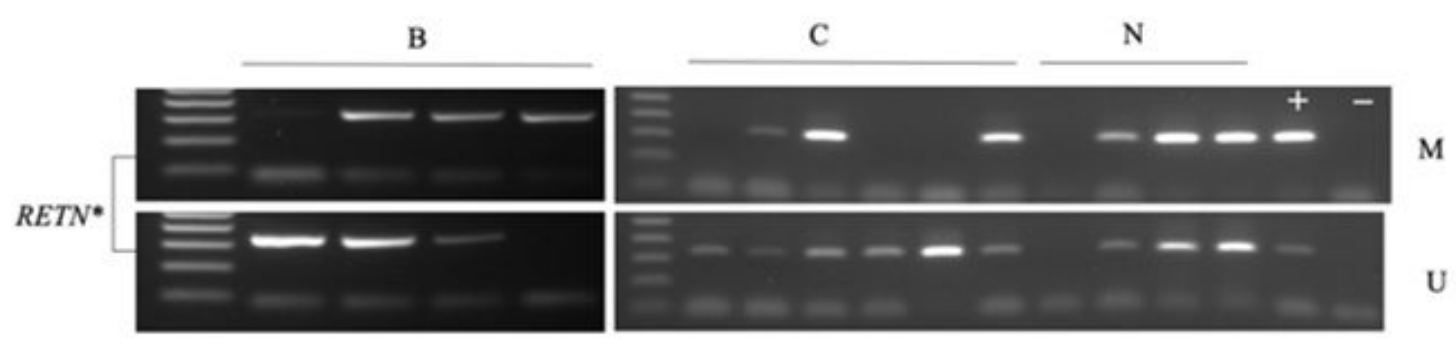

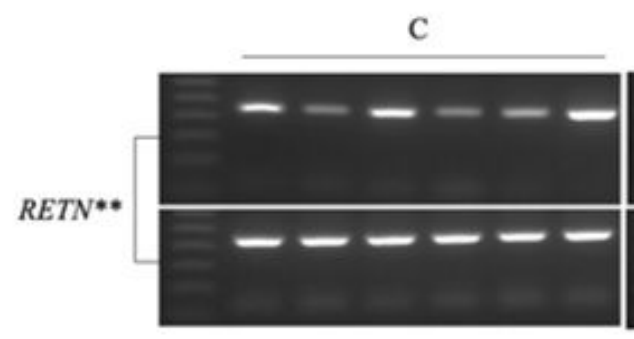

C
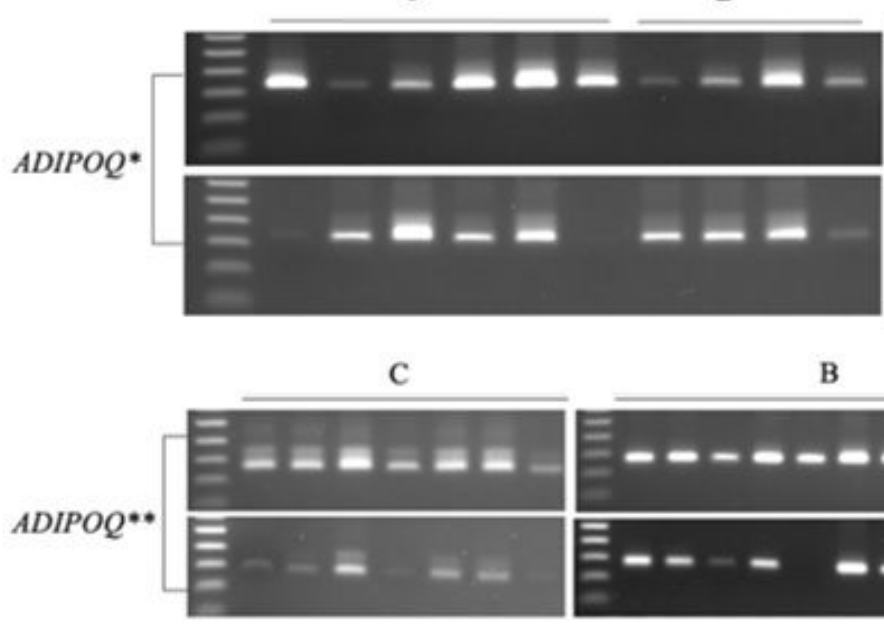

B

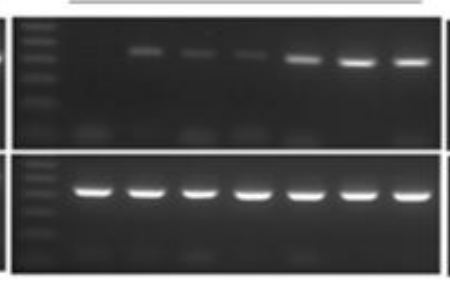

B

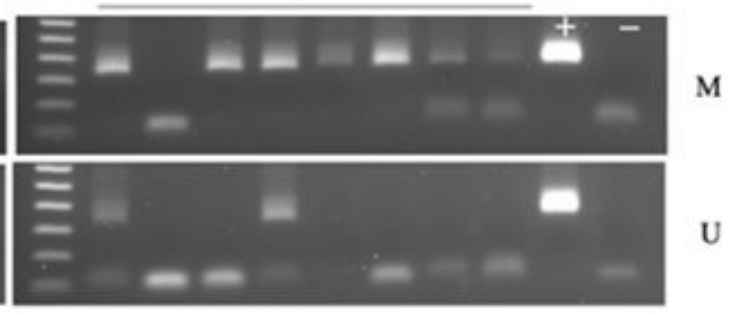

$\mathrm{N}$

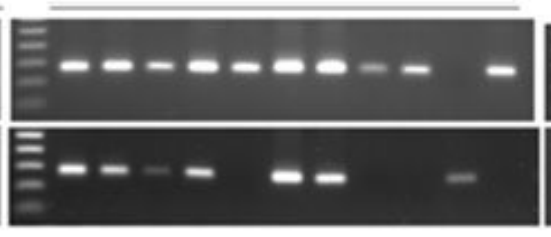

\section{Figure 1}

MS-PCR results of RETN and ADIPOQ genes. Bands represent the MS-PCR results using a set of primers that upper raw shows the results obtained from the $(M)$ methylated primers, whereas lower raw presents $(U)$ unmethylated results for the same samples for each gene targeted region. $C=$ colon cancerous tissue, $B=b l o o d$ pair samples, $\mathrm{N}=$ non-cancerous colon tissue, $(+)=$ positive control, and $(-)=$ negative control. RETN*=region one, product size $=166$ bp. RETN**=exon one, product size= $223 \mathrm{bp}$. ADIPOQ*=region one, product size $171 \mathrm{bp}$. ADIPOQ**=region two, product size for $\mathrm{M}=140, \mathrm{U}=142 \mathrm{bp}$. Marker $50 \mathrm{bp}$ was loaded for all the MS-PCR amplicons.

\section{Supplementary Files}

This is a list of supplementary files associated with this preprint. Click to download.

- Additionalinformation.pdf

- Additionalinformation2.pdf 